\title{
A sound children's mind in a healthy children's body
}

\author{
Marco Taubert ${ }^{1}$ and Burkhard Pleger ${ }^{1,2 *}$ \\ ${ }^{1}$ Department of Neurology, Max Planck Institute for Human Cognitive and Brain Sciences, Leipzig, Germany \\ ${ }^{2}$ Clinic for Cognitive Neurology, University Hospital Leipzig, Leipzig, Germany \\ *Correspondence: bpleger@cbs.mpg.de \\ Edited by: \\ Hauke R. Heekeren, Freie Universität Berlin, Germany \\ Reviewed by: \\ Sabine Schaefer, Max Planck Institute for Human Development, Germany
}

Keywords: children, physical fitness, functional magnetic resonance imaging (fMRI), cognitive control, prefrontal cortex, brain maturation

\section{A commentary on}

The effect of physical activity on functional MRI activation associated with cognitive control in children: a randomized controlled intervention

by Chaddock-Heyman, L., Erickson, K. I., Voss, M. W., Knecht, A. M., Pontifex, M. B., Castelli, D. M., et al. (2013) Front. Hum. Neurosci. 7:72. doi: 10.3389/fnhum.2013.00072

"Mens sana in corpore sano" (i.e., "A sound mind in a healthy body") is possibly one of the phrases in human history with the widest range in meanings. Originally this phrase comes from Satire $X$ of the Roman poet Juvenal ( $\sim 60-127$ AD). Juvenal's intention with this phrase was rather to teach his fellow Roman citizens the right virtues worth praying for, than making any scientific statement about the impact of physical activity on the human mind. But Juvenal's phrase interpreted in the latter context has turned true in light of growing evidence from neurocognitive research suggesting that physical fitness indeed enhances cognitive function (for a review see Hillman et al., 2008).

A more recent but even more important question is how physical activity and training may influence the developing brain during periods in which the brain matures, learns and forms connections (Amso and Casey, 2006). In adult animals and humans, physical exercise was in fact shown to influence the brains cellular and molecular layout by stimulating neurogenesis (e.g., transiently elevating levels of brain-derived neurotrophic factor important for brain plasticity and behavior) in brain regions like the hippocampus, known to underpin memory formation (for a review see Voss et al., 2013). Research like this in children is fundamental for the development of appropriate educational concepts optimally embedding sport activities into children's school day. Reality however speaks a different language, since even in light of previous research indeed suggesting improved cognitive function with enhanced physical fitness (see e.g., Hillman et al., 2009; Pontifex et al., 2011; Voss et al., 2011; Chaddock et al., 2012), opportunities for physical activities for children are progressively reduced, not only in school but also around their home environment (Troiano et al., 2008). At the same time, society is seeking for young sport talents in soccer, football, basketball, hockey, and other famous sports, progressively establishing a selection process segregating children into an inactive group, receiving more school class and less sport education, from those talents being intensively trained for a possible professional sport career.

That this development in sport education might be misleading was already suggested by a number of recent crosssectional studies showing improved cognitive function with enhanced physical fitness (see e.g., Hillman et al., 2009; Pontifex et al., 2011; Voss et al., 2011; Chaddock et al., 2012). The study "The effect of physical activity on functional MRI activation associated with cognitive control in children: a randomized controlled intervention" by Laura Chaddock-Heyman and colleagues has gained a large community-wide interest after publication, since it is the first long-term interventional functional MRI study addressing the open question how physical activity influences cognitive capacity together with the function of specific prefrontal regions in children. The study published in Frontiers in Human Neuroscience in March 2013 is the consequent next step in this research field, since the cross-sectional studies conducted so far bear the risk that instead of the physical training itself, other hidden systematic between-group factors, such as genes and nutrition, may explain why physically active children outperformed their lower fit peers on tasks of cognitive control (Hillman et al., 2009; Pontifex et al., 2011; Voss et al., 2011; Chaddock et al., 2012). Furthermore, only a few studies on children have combined cognitive testing with brain imaging to examine how physical activity and aerobic fitness relate to brain processes of enhanced cognitive function (Hillman et al., 2011). Recent evidence from the few brain imaging studies published so far suggest reduced neural activity in the prefrontal cortex together with improved cognitive function in children with higher aerobic fitness levels (Chaddock et al., 2011; Voss et al., 2011). These findings are in agreement with studies comparing adult's with children's cognitive control capacities demonstrating reduced activity in the frontal cortex of adults coupled with enhanced cognitive performance (see e.g., Diamond, 2006; Bunge and Crone, 2009).

The study design used by ChaddockHeyman and colleagues acknowledges these previous studies also when accounting for the two main problems that occur when investigating the developing brain: First, an interventional study involving children over a longer time period needs to control for the "normal" progress in 
brain maturation over the same period. Secondly, the interpretation of the findings requires a reference or a standard the acquired data can be compared with. To account for these problems, ChaddockHeyman and colleagues selected a study design that allowed comparing the intervention group with two control groups, each addressing one of the two problems. The intervention group was investigated with functional magnetic resonance imaging on a Go/NoGo task before and after a 9 month period of physical activity (i.e., 60 min daily on 5 days per week). To control for the "normal" progress in brain maturation they recruited a control group in the same age range and with comparable educational background that were promised the participation in the same fitness program in future (i.e., socalled "wait-list group"). These subjects also underwent fMRI before and after a 9month period but without participating in any fitness program in between. To address the second problem, namely establishing a reference the findings can be compared with, Chaddock-Heyman and colleagues recruited another control group consisting of college-aged young adults, since adult cognitive capacity together with the related brain function is often characterized as the "mature" or "optimal" model of brain function (Luna et al., 2010).

The study by Chaddock-Heyman and colleagues indicates that after the 9 months of physical training children of the intervention group indeed showed a decreased neural activity in the right anterior prefrontal cortex coupled with improvements in attentional and interference control. These differences in the pre-post comparison cannot be explained by "normal" brain maturation since children of the "wait-list group" did not show any changes neither in brain function, nor in cognitive control. Furthermore, when compared to the reference group consisting of colleague-aged adults, researchers found that children's behavior in the intervention group and brain activation pattern became more comparable to this reference cohort as compared to the "wait-list group."

The findings by Chaddock-Heyman and colleagues demand wide public awareness since they are important with respect to children's health. Physical activity at young age is important in many perspectives, not only to prevent obesity and related diseases, which became a world-leading health burden over the last decades with dramatically climbing incidence rates especially in children, but also for optimally supporting the development of cognitive function and brain maturation. Children and their parents need to learn that being physically active is not only important for their health but also supports their cognitive development and hence enriches their life. Our modern society urgently needs to rethink the misleading development in physical education that should rather encourage each single child to become and stay active, instead of making sport accessible only for talents with possible perspectives in professional sports.

\section{ACKNOWLEDGMENT}

Burkhard Pleger was supported by the BMBF (Bernstein Focus, State Dependencies of Learning 01GQ0975; Project 18GL4DW4).

\section{REFERENCES}

Amso, D., and Casey, B. J. (2006). Beyond what develops when: neuroimaging may inform how cognition changes with development. Curr. Dir. Psychol. Sci. 15, 24-29. doi: 10.1111/j.09637214.2006.00400.x

Bunge, S. A., and Crone, E. A. (2009). "Neural correlates of the development of cognitive control," in Neuroimaging in Developmental Clinical Neuroscience, eds J. Rumsey and M. Ernst (Cambridge, UK: Cambridge University Press), 22-37. doi: 10.1017/CBO9780511757402.005

Chaddock, L., Erickson, K. I., Prakash, R. S., Voss, M. V., Van Patter, M., Pontifex, M. B., et al. (2012). A functional MRI investigation of the association between childhood aerobic fitness and neurocognitive control. Biol. Psychol. 89, 260-268. doi: 10.1016/j.biopsycho.2011.10.017

Chaddock, L., Hillman, C. H., Buck, S. M., and Cohen, N. J. (2011). Aerobic fitness and executive control of relational memory in preadolescent children. Med. Sci. Sports Exerc. 43, 344-349. doi: 10.1249/MSS.0b013e3181e9af48

Diamond, A. (2006). "The early development of executive functions," in Lifespan Cognition: Mechanisms of Change, eds E. Bialystok and F. I. M. Craik (NewYork, NY: Oxford University Press), 70-95. doi: 10.1093/acprof:oso/9780195169539.003.0006
Hillman, C. H., Buck, S. M., Themanson, J. R., Pontifex, M. B., and Castelli, D. M. (2009). Aerobic fitness and cognitive development: event-related brain potential and task performance of executive control in preadolescent children. Dev. Psychol. 45, 114-129. doi: 10.1037/a0014437

Hillman, C. H., Erickson, K. I., and Kramer, A. F. (2008). Be smart, exercise your heart: exercise effects on brain and cognition. Nat. Rev. Neurosci. 9, 58-65. doi: 10.1038/nrn2298

Hillman, C. H., Kamijo, K., and Scudder, M. (2011). A review of chronic and acute physical activity participation on neuroelectric measures of brain health and cognition during childhood. Prev. Med. 52(Suppl. 1), 21-28. doi: 10.1016/j.ypmed.2011.01.024

Luna, B., Padmanabhan, A., and O'Hearn, K. (2010). What has fMRI told us about the development of cognitive control through adolescence? Brain Cogn. 72, 101-113. doi: 10.1016/j.bandc.2009.08.005

Pontifex, M. B., Raine, L. B., Johnson, C. R., Chaddock, L., Voss, M. W., Cohen, N. J., et al. (2011). Cardio-respiratory fitness and the flexible modulation of cognitive control in preadolescent children. J. Cogn. Neurosci. 23, 1332-1345. doi: 10.1162/jocn.2010.21528

Troiano, R. P., Berrigan, D., Dodd, K. W., Masse, L. C., Tilert, T., and McDowell, M. (2008). Physical activity in the United States measured by accelerometer. Med. Sci. Sports Exerc. 40, 181-188. doi: 10.1249/mss.0b013e31815a51b3

Voss, M. W., Chaddock, L., Kim, J. S., Van Patter, M., Pontifex, M. B., Raine, L. B., et al. (2011). Aerobic fitness is associated with greater efficiency of the network underlying cognitive control in preadolescent children. Neuroscience 199, 166-176. doi: 10.1016/j.neuroscience.2011.10.009

Voss, M. W., Vivar, C., Kramer, A. F., and van Praag, H. (2013). Bridging animal and human models of exercise-induced brain plasticity. Trends Cogn. Sci. 17, 525-544. doi: 10.1016/j.tics.2013. 08.001

Conflict of Interest Statement: The authors declare that the research was conducted in the absence of any commercial or financial relationships that could be construed as a potential conflict of interest.

Received: 24 April 2014; accepted: 22 May 2014; published online: 10 June 2014.

Citation: TaubertM and Pleger B (2014) A sound children's mind in a healthy children's body. Front. Neurosci. 8:143. doi: 10.3389/fnins.2014.00143

This article was submitted to the journal Frontiers in Neuroscience.

Copyright (C) 2014 Taubert and Pleger. This is an openaccess article distributed under the terms of the Creative Commons Attribution License (CC BY). The use, distribution or reproduction in other forums is permitted, provided the original author(s) or licensor are credited and that the original publication in this journal is cited, in accordance with accepted academic practice. No use, distribution or reproduction is permitted which does not comply with these terms. 